\title{
Asset Allocation: An Application Of The Analytic Hierarchy Process
}

\author{
Steven V. Le, .California State University, Long Beach, USA
}

\begin{abstract}
The objective of this paper is to develop a theoretically sound approach for determining the appropriateness of an investment allocation for a particular investor. A methodology using an Analytic Hierarchy Process (AHP) is suggested as a means of formalizing the process of determining the suitability of a potential investment portfolio to a potential investor. The AHP has been applied to a variety of business decisions and processes requiring high degrees of subjective judgment. The result of this model is an asset allocation scheme tailored to the specific requirements of an individual investor. Although the AHP process is a subjective weighting technique that relies upon the judgment of the decision-maker, it does so in a manner that is more systematic and consistent than traditional subjective decision-making.
\end{abstract}

Keywords: investment, asset allocation, Analytic Hierarchy Process (AHP), decision-making, subjective weighting technique, potential investment, business decisions.

\section{INTRODUCTION}

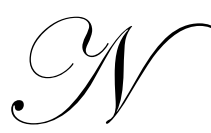

ew York Stock Exchange Rule 405 and American Stock Exchange Rule 411 specify that stock brokers should "exercise due diligence" in determining essential facts about their clients. The

National Association of Securities Dealers, the Municipal Securities Rule Making Board, the Chicago Board Options Exchange, and most importantly, the Securities and Exchange Commission also require brokers to learn relevant facts about their clients and refrain from making investment recommendations that would be considered unsuitable. Regulators, however, do not explicitly state how to determine suitability.

Suitability refers to the appropriateness of particular investments and portfolios of investments for specific investors. Because the definition of suitability is a subjective, there exists the potential for inconsistent assessments of suitability across clients at a single point in time or for a single client at different points in time.

Determining the suitability of an investment is of critical importance because disappointed investors can make various legal claims regarding the inappropriate handling of their accounts by investment professionals. In fact, unsuitability is one of the most common complaints disgruntled investors make. A suitability claim can be alleged under Section 10b and Rule 10b-5 of the Securities and Exchange Act of 1934 as a violation of the selfregulatory organization rules or under state laws. In 1991, Charles Schwab \& Company, a discount broker, not offering investment advice was held liable at an arbitration hearing for losses a client suffered by trading stock options. The arbitrators felt that Charles Schwab had a duty to protect the clients from their own carelessness.

The formal subjective model presented in this paper is based on the AHP. The application of the model uses the essential investor characteristics derived from NYSE Rule 405. Once the model developer determines the relative importance of each of these characteristics, the resulting structure can be used repeatedly to examine a variety of investor situations. 


\section{METHODOLOGY}

The AHP process is useful for systematically evaluating qualitative criteria. AHP attempts to resolve conflicts and analyze judgments through a process of determining the relative importance of a set of activities or criteria. The AHP can be summarized in terms of three basic components. First, the principal problem is decomposed into a hierarchy. The top level of the hierarchy represents the overall objective of the process. For example, if evaluating the riskiness of a corporate bond, the top level could be labeled "credit-worthiness". In the approach discussed in this paper, this top level is investment suitability. Once the top level of the hierarchy has been defined, then the overall objective of the process is broken down into components. These factors compose the second level of the hierarchy. Subsequently, each element in the second level spans a group of sub-elements in the third level. This process is repeated until the final level is reached. The final level represents the array of possible outcomes. In this case, the array of possible outcomes is the weightings of various assets held in a portfolio.

Once the decision hierarchy has been modeled; the second phase of the process must be addressed. Within each level of the hierarchy, the relative importance of all elements derived from a single element in the next higher level must be determined. For example, suppose element 1 in level 2 is decomposed in level 3 into three subelements, $\alpha, \beta$, and $\gamma$. The AHP determines the relative importance of these three sub-elements by constructing a complete set of pairwise comparisons among them. A nine-point scale is used for these comparisons. A score of 9 signifies the highest level of importance for an element relative to other elements, and a score of 1/9th signifies an element is much less important. If comparison $\alpha$ to $\beta$ is assigned a $1, \alpha$ and $\beta$ are considered of equal importance. The comparison of $\beta$ to $\alpha$ would be assigned the reciprocal value. Interpretations for the pairwise comparisons are summarized in Table I. A complete set of such scores constitutes a pairwise comparison matrix. At the final level of the hierarchy each possible outcome must be considered relative to a single sub-element of the previous level. For example, a sub-element of the bond rating process might be "management strength". The expert must consider all possible pairs of bond-rating categories as they relate to strength of management.

In the third and final phase of the AHP, the pairwise comparison matrices are evaluated by solving for their eigenvalues. The eigenvalues represent the weighting functions for each set of pairwise comparison matrices. Each set of lower level eigenvalues is then scaled by the eigenvalues corresponding to the next level in the hierarchy. Continuing the process of eigenvalue extraction and weighting through the levels of the hierarchy leads to a global weighting scale. The global priorities for the final level reflect the decision-maker's relative weights for the alternatives.

Setting up a problem as a hierarchy is an efficient and intuitive way of dealing with complexity and identifying the relevant components of the problem. Although the process may appear cumbersome, personal computer based applications that automate this process are currently available. The AHP is flexible in allowing decision-makers to structure a hierarchy to fit individual needs and preferences. In addition, used in a group setting, using AHP to structure a problem may help to isolate areas of disagreement so that more attention can be focused on them in order to achieve consensus.

\section{ANALYSIS APPROACH}

In developing an AHP model for determining suitability, three major investment suitability attributes were identified: investment goals, financial need, and level of investor sophistication. These major attributes were further decomposed into 13 sub-elements. Table II provides a definition of each of the 13 sub-elements. In addition, seven hypothetical investment options were considered. In order of riskiness the investment options are: T-bills, government bonds, corporate bonds, utility stocks, blue chip stocks, growth stocks, and derivative securities. Four categories of investors were considered in this analysis:

- An unmarried blue-collar worker, age 25, with no dependents. The investor desires a high return over the next five years and has a high tolerance for risk. The major source of income is wages of $\$ 30,000$, and liquid net worth of $\$ 5,000$. The investor has a high school diploma and no investment experience.

a A young married couple, each 32 years old, with two children. The investors have MBA degrees. They 
have a combined salary of $\$ 120,000$, and liquid net worth of $\$ 15,000$. The couple has an above-average level of expected return and risk tolerance over the next three years.

- A middle-aged couple with four children, two of whom are in college. The couple has an average level of expected return and a low tolerance for risk. Their combined income is $\$ 80,000$ with a net worth of $\$ 50,000$. Both investors have college degrees. The couple has an auto loan and a mortgage.

- A retired couple with a pension income of $\$ 15,000$ and liquid net worth of $\$ 100,000$. The couple has no debt. They expect and average level of return and have almost no risk tolerance. Each has a high school diploma.

A summary of the attributes for these four types of investors is provided in Table III.

An overall hierarchical representation of the suitability determination process yields a hierarchy consisting of four levels. The first level represents the overall goal of the process: suitability. The three major investor characteristics-investment goals, financial needs, and level of sophistication-form the second level of the hierarchy. Each of the three categories is broken down into various sub-elements forming the third level. Each sub-element is related to the seven investment options forming the fourth level. A graphical representation of the hierarchy is presented in Figure I.

The analysis approach then is to first rank the elements (or group of sub-elements) and then assign pairwise comparison scores that capture this information. For example, after careful consideration, financial needs is ranked as the most important element of its level. This element is followed by investment goals and level of sophistication. After further discussion, it is determined that the pairwise scores for financial needs to investment goals is 2 , and financial needs to level of sophistication is 4 .

To use the AHP, a $3 \times 3$ matrix is constructed, requiring nine pairwise comparisons, in reality this step is not difficult because the three "diagonal" comparisons assess each element's importance relative to itself (always 1) and the reciprocal comparisons will be assigned reciprocal scores. For example, investment objectives to financial needs will be one-half and level of sophistication to financial needs will be one-fourth. At this point, seven of the nine pairwise comparisons have been completed. The only remaining comparisons are investment objectives to level of sophistication and level of sophistication to investment objectives. Scores of 3 and $1 / 3^{\text {rd }}$ are assigned to these comparisons, respectively. The scores are summarized in the following matrix (where $\mathrm{FN}=$ financial needs, $\mathrm{JO}=$ investment objectives, and $\mathrm{SP}=$ level of sophistication):

\begin{tabular}{|c|c|c|c|}
\hline & $I G$ & $F N$ & $S P$ \\
\hline IG & $\sqrt{T}$ & $1 / 2$ & 3 \\
\hline FN & 2 & 1 & 4 \\
\hline SP & $1 / 3$ & $1 / 4$ & 1 \\
\hline
\end{tabular}

After determining the initial ordering from 1 to 9 for all sub-elements of all sub-elements within a group, subsequent pairwise comparisons were easily determined. Table IV reports the pairwise elements for the initial ranking of each of the three groups of sub-elements.

Once the comparison matrix is complete, the AHP process then requires that the eigenvalues of the array be determined. The eigenvalues are used as weights for the sub-elements. These weights are referred to as local weights and are modified by the local weights of the element they relate to in the next level of the hierarchy. For example, as reported in Table IV, the local weight for occupation is 0.0427 . Because occupation is a sub-element of financial need, which has a local weight of 0.5584 , the global weight of occupation is $(0.0427)(0.5584)$ or 0.0238 .

Once these weights have been determined for suitability factors that are common to all investors, additional comparisons must be provided that represent the profiles of individual investors. 


\section{RESULTS}

The results of using the AMP model to choose portfolios for each of the four hypothetical investors are summarized in Figures II, which shows suitable asset allocation percentages of each of the seven investment securities considered. The asset allocation distributions range from a heavier concentration in high-risk assets for the single investor to a heavier concentration in low-risk assets for the retired couple. The results (based on criteria proposed for each investor) suggest the following allocations:

- The single person should invest $57.4 \%$ of asset in stocks and derivatives, and $42.6 \%$ in bonds and T-Bills.

a The young couple should invest $71 \%$ in stocks and derivatives, and smaller percentages in government bonds and T-bills.

a The middle-aged couple should invest $42.7 \%$ in stocks and small percentage in derivatives, with large percentages also invested in government, corporate bonds and T-bills.

a The retired couple should invest primarily in T-bills, government bonds, and corporate bonds. Smaller percentages are invested in utility stocks, blue chip stocks, growth stocks, and derivatives.

\section{SUMMARY AND CONCLUSIONS}

In recent years, an increasing number of disgruntled investors have filed complaints against stock brokers and investment firms that have recommended investments that did not produce the desired results; often these complaints allege unsuitability. The SEC and the various national and regional exchanges require brokers to consider suitability when recommending investments to clients. However, no formal determination of suitability is specified. The AHP process is one approach, which could be utilized by brokers and brokerage houses to formalize the suitability determination process. The suitability of each investment differs for each investor. The model finds that a moderate amount of high-risk securities, such as options, futures, and high-growth stocks is suitable for younger investors willing to bear some risk, but a smaller percentage should be held in the portfolios of older investors. Not surprisingly, the model indicates that all investors should diversify their investment portfolio with the weights adjusted to reflect risk preferences.

\section{List of Tables}

Table I: - Fundamental Scale for AHP

\begin{tabular}{|c|c|}
\hline Ratings of Absolute Importance & $\begin{array}{l}\text { Explanation } \\
\end{array}$ \\
\hline$\alpha$ to $\beta=1$ & Two activities contribute equally to the objective and are of the highest importance \\
\hline$\alpha$ to $\beta=3$ & Experience and judgment moderately favor $\alpha$ over $\beta$. \\
\hline$\alpha$ to $\beta=5$ & Experience and judgment strongly favor $\alpha$ to $\beta=3$ over $\beta$. \\
\hline$\alpha$ to $\beta=7$ & $\alpha$ is strongly favored over $\beta$ and its dominance is demonstrated in practice. \\
\hline$\alpha$ to $\beta=9$ & The evidence favoring $\alpha$ over $\beta$ is the highest possible. \\
\hline$\alpha$ to $\beta=2,4,6,8$ & When compromise is needed \\
\hline Reciprocals & $\begin{array}{l}\text { If activity } \alpha \text { has one of the above numbers assigned to it when compared with activity } \\
\beta \text {, then } \beta \text { has the reciprocal value when compared to } \alpha \text {. For example, if } \alpha \text { to } \beta \text { is } 2 \text {, then } \\
\beta \text { to } \alpha \text { is } 1 / 2\end{array}$ \\
\hline
\end{tabular}


Table II - Attribute and Sub-Element Definitions for Suitability

\begin{tabular}{|c|c|}
\hline Attribute & Definition \\
\hline 1. Investment Goals & Captures the investor's expectation of investment performance. \\
\hline - Level of Expected Return & The level of return that the investor desires. \\
\hline - Risk Tolerance & The level of risk the investor is willing to assume. \\
\hline - Time Horizon & The length of time the investor is willing to maintain their investment position. \\
\hline - Liquidity & $\begin{array}{l}\text { Being able to convert the investment quickly into cash without substantial loss in } \\
\text { value. }\end{array}$ \\
\hline 2. Financial Need & $\begin{array}{l}\text { Captures the investor's financial position, future sources of income, and cash } \\
\text { outflows. }\end{array}$ \\
\hline - Age & High-risk investments are generally more suited to younger investors. \\
\hline - Marital Status & Single investors should be able to assume greater risk than married investors. \\
\hline - Dependents & The more dependents the less suitable high-risk investments will be \\
\hline - Occupation & $\begin{array}{l}\text { Occupation may affect the stability of income and understanding of different } \\
\text { investment vehicles. }\end{array}$ \\
\hline - Income Source & $\begin{array}{l}\text { Investors with stable, low-risk sources of income will be able to tolerate riskier } \\
\text { investments. }\end{array}$ \\
\hline - Income Level & The level of annual income directly correlates to the ability to assume greater risk. \\
\hline - Net Worth & $\begin{array}{l}\text { The greater the amount of liquid net worth, the greater the ability to assume more } \\
\text { risk. }\end{array}$ \\
\hline 3. Level of Sophistication & Captures for the investor's ability to understand risk and risky investments. \\
\hline - Investment Experience & $\begin{array}{l}\text { The investment experience of the investor will influence the suitability of investment } \\
\text { vehicles. }\end{array}$ \\
\hline - Education & Education allows investors to evaluate the nature of risky investments better. \\
\hline
\end{tabular}


Table III - Investor Attributes

\begin{tabular}{|c|c|c|c|c|}
\hline Attributes & Single Person & Young Couple & Middle-Aged Couple & Retired Couple \\
\hline Level of Expected Returns & High & Above Average & Average & Average \\
\hline Risk Tolerance & High & Above Average & Low & Very Low \\
\hline Time Horizon & 5 years & 3 years & 1 year & 1 year \\
\hline Liquidity & Low & Moderate & High & High \\
\hline Age & 25 & 32 & 45 & 70 \\
\hline Marital Status & Single & Married & Married & Married \\
\hline Total Number of Dependents & 1 & 4 & 6 & 2 \\
\hline Occupation & Blue Collar & White Collar & White Collar & Retired \\
\hline Source of Income & Wages & Salary & Salary & $\begin{array}{c}\text { Pension/ } \\
\text { Investment } \\
\text { Income }\end{array}$ \\
\hline Annual Income & $\$ 30,000$ & $\$ 120,000$ & $\$ 80,000$ & $\$ 15,000$ \\
\hline Liquid Net Worth & $\$ 5,000$ & $\$ 15,000$ & $\$ 50,000$ & $\$ 100,000$ \\
\hline Investment Experience & None & High & Bank CD & Bank CD \\
\hline Education & High School & MBA & College & High School \\
\hline
\end{tabular}

Table IV - AHP Model For Determining Investor Suitability

\begin{tabular}{|l|c|c|}
\hline \multicolumn{1}{|c|}{ Element } & Pairwise Comparisons & Local Weights \\
\hline Investment Goals & 2 & 0.3196 \\
Level of expected return & 3 & 0.1793 \\
Risk tolerance & 1 & 0.4777 \\
Time horizon & 2 & 0.2937 \\
Liquidity & 7 & 0.0493 \\
Financial Needs & 1 & 0.5584 \\
Age & 3 & 0.1022 \\
Marital Status & 5 & 0.0427 \\
Dependents & 3 & 0.1022 \\
Occupation & 5 & 0.0427 \\
Source of income & 2 & 0.1676 \\
Annual income & 1 & 0.2445 \\
Liquid net worth & 1 & 0.2981 \\
Level of Sophistication & 4 & 0.1220 \\
Education & 6 & 0.1429 \\
Investment experience & 1 & 0.8571 \\
\hline
\end{tabular}




\section{List of Figures}

Figure I - The Analytic Hierarchy

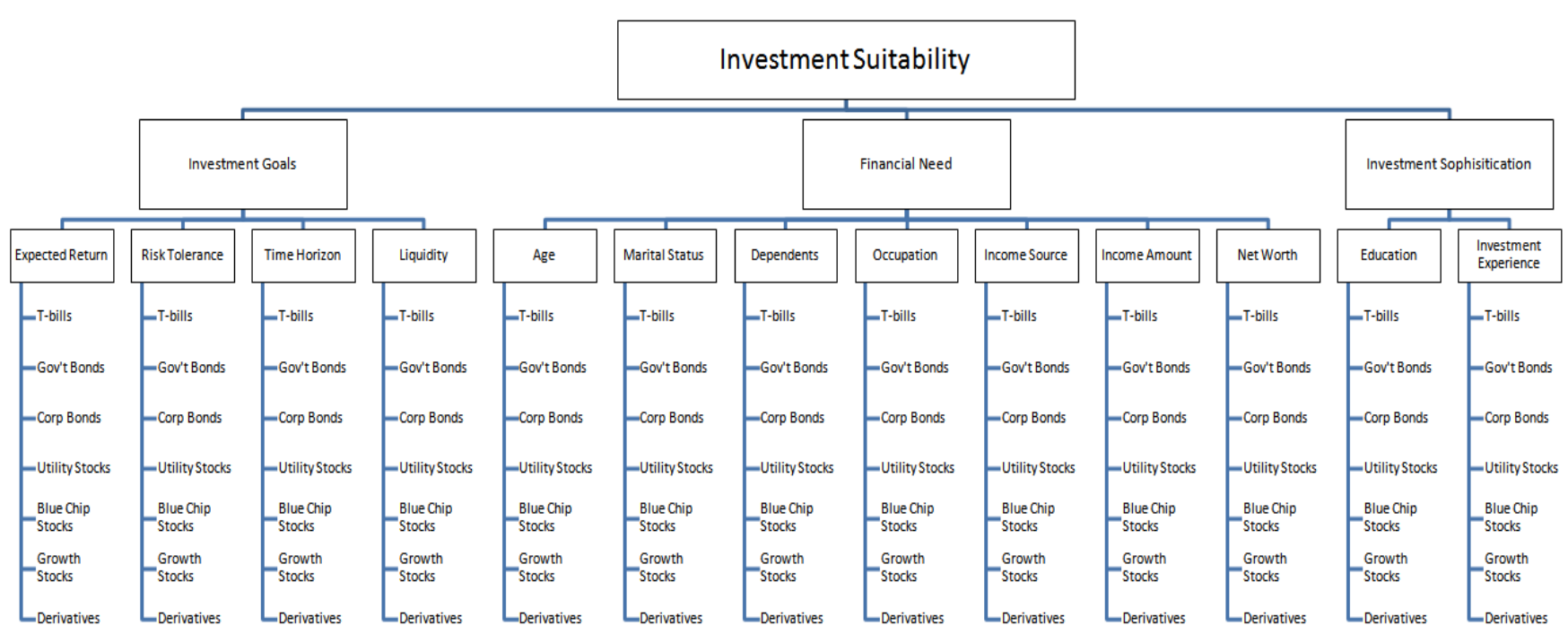

Figure II - Asset Allocation - Single Investor, Young Couple, Middle-Aged Couple, Retired Couple

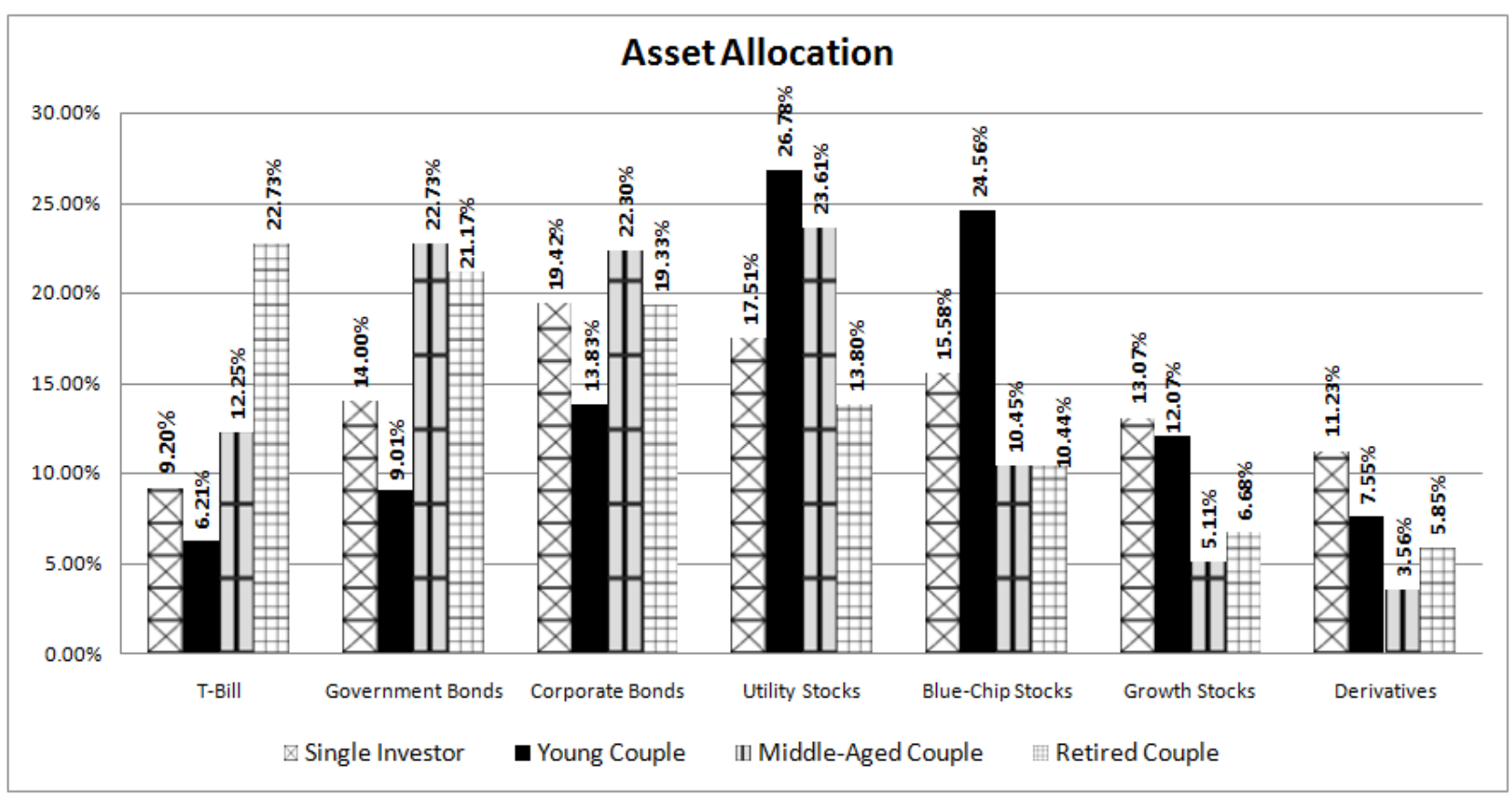

\section{AUTHOR INFORMATION}

Steven Le is Professor of Finance at California State University, Long Beach. He was a Portfolio Manager and Investment Banker at a U.S. Financial Institution. 


\section{BIBLIOGRAPHY}

1. Barrack, L., "Stockbroker Liability and Unsuitability are Common Claims Against Brokers"; Trial, vol. 23, no. 4 (April 1987).

2. Brigham, Eugene F, and Louis C. Gapenski, Intermediate Financial Management, Forth Worth: (The Dryden Press, 1996).

3. Chambers, D.R. and J.S. Zdanowicz, "Stockbroker-Customer Disputes", Trial, vol. 24, no. 7 (July 1988).

4. Dennis, J.P., "Arbitration of Broker-Investor Unsuitability Claims: The Role of the Financial Expert", Financial Practice and Education, vol. 3, no. 2 (Fall 1993).

5. Gillis, J.G. and E.C. Hewitt, "Suitability”, Financial Analysts Journal, vol. 35, no. 5 (September/October 1979)

6. Goforth, C.R., "Stockbrokers Duties to Their Customers", St. Louis University Law Journal, vol. 33, no. 2 (Winter 1989).

7. Khaksari, S., Kamath R., and R. Grieves, "A New Approach to Determining Optimum Portfolio Mix", The Journal of Portfolio Management, vol. 15, no.3 (Spring 1989).

8. Radcliffe, Robert C., Investment Concepts, Analysis, Strategy, Reading, Massachusetts: (Addison-Wesley, 1997).

9. $\quad$ Saaty, T. L., The Analytic Hierarchy Process, New York: (McGraw-Hill, 1980).

10. Zhedi, F., "The Analytic Hierarchy Process-A Survey of the Method and Applications", Interfaces, vol. 16, no. 4(1986).

\section{NOTES}

